\title{
A STUDY OF BRANCHING PATTERNS IN BAZZANIA (JUNGERMANNIALES, LEPIDOZIACEAE)
}

\author{
DAVID MEAGHER
}

\begin{abstract}
Branching patterns in the leafy liverwort genus Bazzania Gray were investigated in twenty-five Australasian species. Terminal branching was found to be neither consistently sinistrorse nor consistently dextrorse, and neither consistently homodromous nor consistently antidromous. Microphyllous ventral-intercalary branches arising from stems usually have 'siblings' arising from main branches. The production of leafy ventral-intercalary branches is not necessarily associated with the termination of stems or main branches. These results are contrary to previous ideas about branching in Bazzania.
\end{abstract}

Key words: Bazzania, branching, Lepidoziaceae, liverwort

David Meagher, School of Botany, The University of Melbourne, Victoria, Australia; e-mail: dameag@unimelb.edu.au

\section{INTRODUCTION}

Branching patterns in leafy liverworts have been studied intensively since the pioneering studies by Leitgeb (1871) and have been used to separate families, genera and subgenera. There are two universally recognised fundamental modes of branching in leafy liverworts: (1) terminal branching, in which branches develop close to the growing tip of the stem from a cortical cell, and (2) intercalary branching, in which branches arise from the stem medulla, so that the developing branch ruptures the cortex, leaving behind a collar of cortical cells around the base of the branch (Schuster 1984). The family Lepidoziaceae, in which the genus Bazzania Gray is positioned, is unusual in having both types of branching commonly developed in the same plant (Crandall 1969).

\section{MATERIAL AND METHODS}

To understand the branching patterns in Bazzania better, I studied the type and frequency of different branches in 25 Australian species. Ten plant segments were selected at random from a single collection of each species and inspected under a dissecting microscope. I recorded the frequency and location of different types of terminal branching and intercalary branching. The results of these observations are presented and discussed in the following sections.

\section{SPECIMENS EXAMINED}

Bazzania accreta (Lehm. \& Lindenb.) Trevis. - HO312267

Bazzania adnexa (Lehm. \& Lindenb.) Trevis. var. adnexa - DAM-1526 (MELU)

Bazzania amblyphylla Meagher - CBG-9519195

Bazzania corbieri (Stephani) Meagher - DAM-551 (MELU)

Bazzania densa (Sande Lac.) Schiffn. - DAM-1112 (MELU)

Bazzania fasciculata (Stephani) Meagher - NSW-605694 Bazzania filiformis Stephani - MELU-133

Bazzania francana (Stephani) N. Kitag. - MELU-3210 Bazzania fuhreri Meagher - DAM-918 (MELU)

Bazzania gedeana (Stephani) Meijer - CBG-8406634

Bazzania hochstetteri (Reicht) E. A. Hodgs. - CBG8113195

Bazzania involuta (Mont.) Trevis. - HO-87423

Bazzania mittenii (Stephani) Stephani - CBG-9409850 Bazzania monilinervis (Lehm. \& Lindenb.) Trevis. DAM-1533 (MELU)

Bazzania nitida (F. Weber) Grolle - CANB-9606105 Bazzania novae-zelandiae (Mitt.) Besch. \& C. Massal. - HO-522693

Bazzania parisii (Stephani) N. Kitag. - CANB-360583 p.p. Bazzania rimosa Meagher - CANB-174171

Bazzania sauropoda Meagher - DAM-N001 (MELU)

Bazzania sp. 'Port Davey' - HO-522564 
Bazzania tessellata Meagher - MUCV-7397 (MELU) Bazzania tayloriana (Mitt.) Kuntze- MELU-3212

Bazzania vittata (Gottsche) Trevis. - DAM-4285 (MELU)

Bazzania wattsiana (Stephani) Meagher - CBG-9008609 Bazzania zonulata Meagher - DAM-1272 (MELU)

\section{RESULTS}

\section{TERMINAL BRANCHING IN BAZZANIA}

In Bazzania each branch develops from the anterior end of the merophyte and replaces half a leaf, and the growth of the branch occurs at the same time as the continuing growth of the stem, so that the stem is usually displaced laterally (Fig. 1a). Such branching is called 'acroscopic' and is found in many leafy liverwort families. Furthermore, each branch in Bazzania always replaces the 'ventral half' of a leaf (that is, the portion of the leaf attached to the ventral half of the stem), leaving a half-leaf (the 'dorsal half-leaf') in the dorsal axil of the branch. Such a branch is known as a Frullania-type branch (Fig. 1b). Other types of acroscopically derived branching in leafy liverworts are (a) Microlepidozia-type in which each branch replaces the dorsal half of a leaf, thus leaving a half-leaf in the ventral axil of the branch, (b) Acromastigum-type in which each branch alternately replaces one half and then the other half of a whole leaf, so that ventral half-leaves alternate with dorsal half-leaves in the axils of the branches, and (c) Zoopsis-type, in which each branch replaces all of a leaf, leaving no leaf remnants in the axils of the branches (Fig. 1c-e).

Since the studies of Leitgeb (1871) it has been accepted that terminal branches in Bazzania are always 'homodromous'; that is, they arise always from the same side of the stem in any particular plant (Fig. 2a). Branching from both sides of the stem on the one plant is termed 'antidromous'
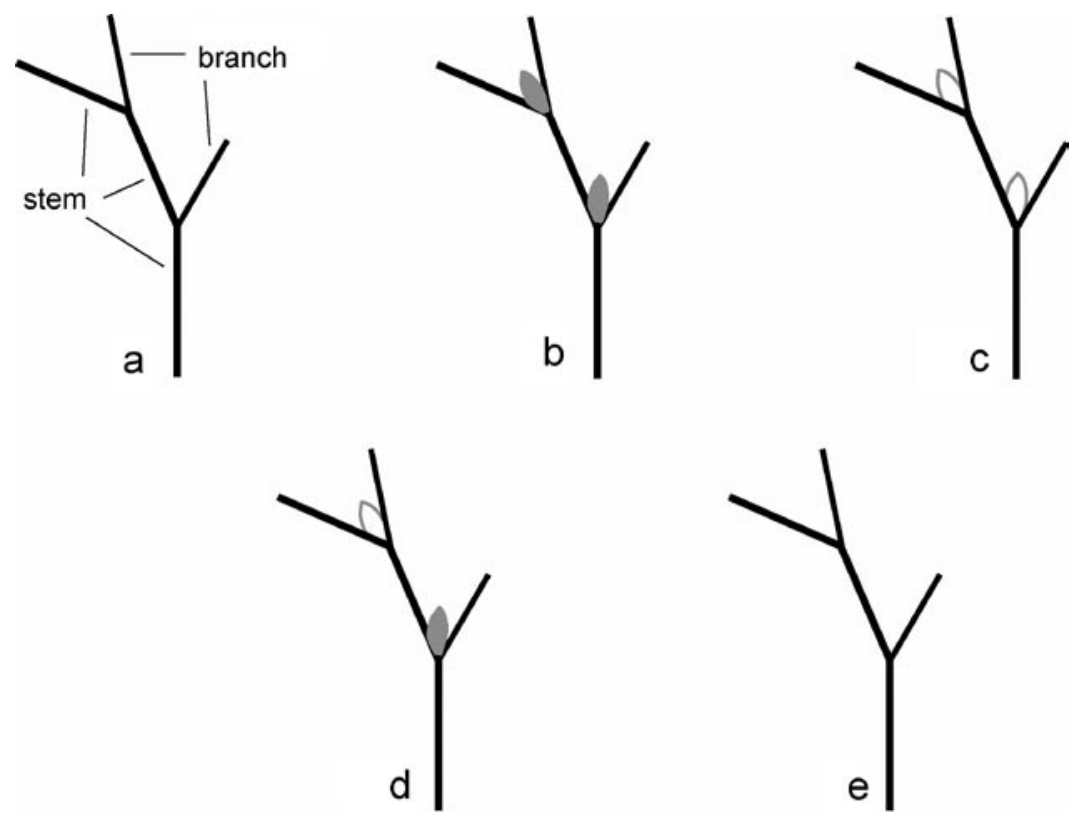

Fig. 1. Acroscopic branching in leafy liverworts. a - Acroscopic branching, in which the stem is displaced to one side at each branch junction. b - Frullania-type branching, in which a half-leaf remains on the dorsal side of each branch junction. $\mathrm{c}$-Microlepidozia-type branching, in which a half-leaf remains on the ventral side of each branch junction. $\mathrm{d}-$ Acromastigumtype branching, in which a half-leaf remains on the dorsal side of one branch junction, but on the ventral side of the next junction. e - Zoopsis-type branching, in which each branch replaces the whole of a leaf, leaving no half-leaf in the branch junction. (All diagrams as seen from the dorsal side of the stem. Solid grey represents a dorsal half-leaf; outline grey represents ventral half-leaf). 
(Fig. 2b). Schuster and Schofield (1982) supported this view, having examined hundreds of shoots in 12 species of Bazzania and found that the branching was always homodromous, although sometimes left-hand (sinistrorse) and sometimes right-hand (dextrorse) when viewed from the dorsal side of the stem. They contrasted this finding with that of Evans (1912), who examined numerous genera of Lepidoziaceae with Frullania-type branching and found that they often had both left-hand and right-hand branches on the same shoot, so that the plants could be either homodromous or antidromous (the notable exception being Bazzania). Schuster and Schofield (1982) found this to be the case also in Dendrobazzania R. M. Schust. \& W. B. Schofield.

The direction of branching is easy to determine in Bazzania, because in Frullania-type branching a reduced underleaf occurs on the branch side of the stem, the result of 'the restricted part of the segment which takes part in its formation' (Evans 1912).

It is significant that in some species both left-hand and right-hand branches were found on the same shoot, although often dominated by branching from one side (see Fig. 4). This antidromous branching was most common in B. filiformis Stephani, occurring on 8 of 10 multiply branched shoots.

Thus the direction of terminal branching in Bazzania is not always constant, and whether it is left-hand or right-hand appears to be random. The claims of Leitgeb (1871) and Schuster and Schofield (1982), although perhaps true for some species, are therefore invalid for Bazzania in general.

It is often stated that terminal branching in Bazzania is always pseudodichotomous, but in some species terminal branching hardly displaces the stem, so that the branching might be termed 'pseudolateral' rather than pseudodichotomous, as Engel and Merrill (1994) noted. In these cases the branches are much weaker than the stem and the plants lack the characteristic Y-branched appearance of most species. The only Australasian Bazzania taxa known to have such pseudolateral branching are B. involuta (Mont.) Trevis. and B. fasciculata (Stephani) Meagher. Bazzania

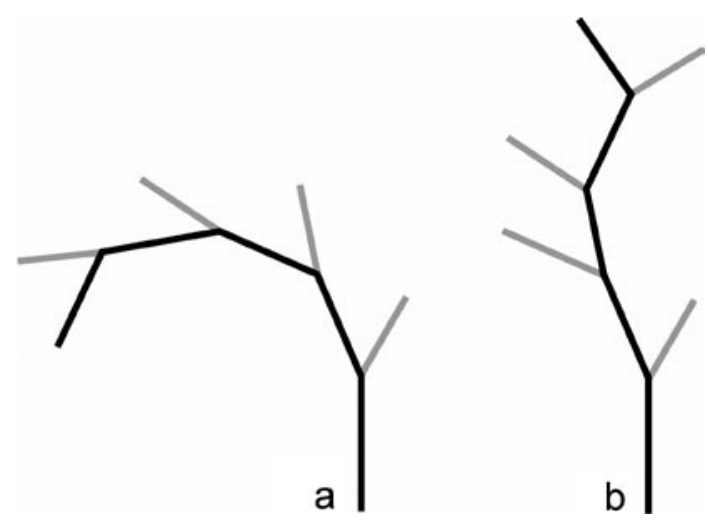

Fig. 2. Homodromous (a) and antidromous (b) branching. Branches shown grey for clarity.

involuta usually has an upright growth habit that is very rare in Bazzania, whereas B. fasciculata is procumbent and often has both pseudolateral and pseudodichotomous branching.

\section{INTERCALARY BRANCHING IN BAZZANIA}

Intercalary branching may be lateral or ventral; that is, the branches may develop from either lateral or ventral merophytes. In Bazzania it is always ventral-intercalary - Grolle (1964) therefore called ventral-intercalary branching ' $\mathrm{Baz}$ zania type' - and may give rise to four sorts of branches, each of which arises in the distal axil of an underleaf:

- microphyllous branches - long, thin branches bearing minute leaves and underleaves that are very different from those on the stems and branches (Fig. 3a)

- leafy branches - branches bearing more or less normal leaves and underleaves, although often smaller than those on the stems and branches (Fig. 3b)

- gynoecial branches - very short branches bearing gynoecia, usually but not always in the distal part of a shoot (Fig. 3c)

- androecial branches - very short branches bearing androecia (Fig. 3d); according to Schuster (2000) these arise usually in the proximal portion of a shoot, but this is often not the case, e.g., in B. gedeana (CBG-8406634) they occur from the very proximal to the very distal parts of a shoot. 
a
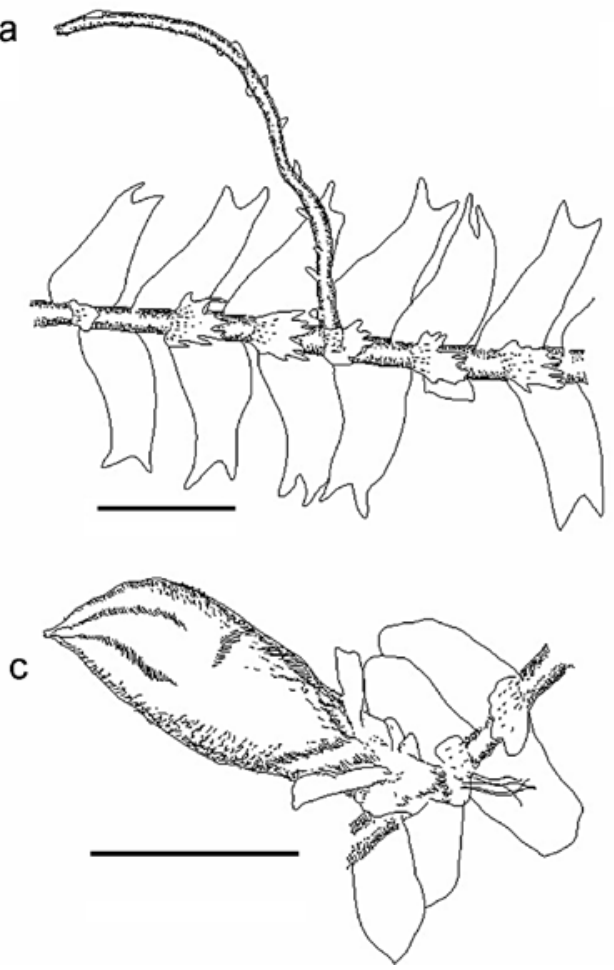

b
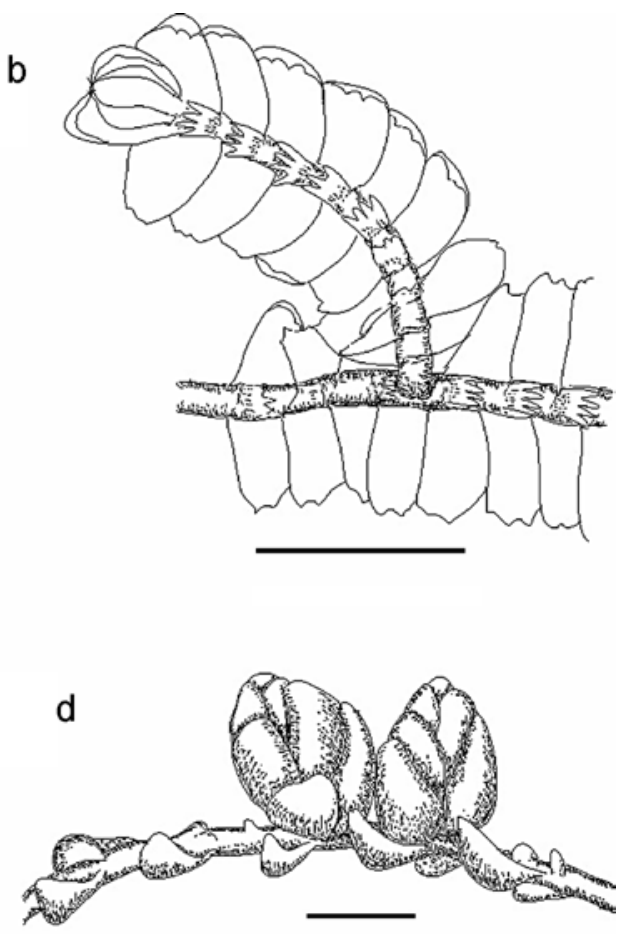

Fig. 3. Ventral-intercalary branches in Bazzania Gray. a - microphyllous branch, B. scalaris Meagher. b - leafy branch, B. nitida (F. Weber) Grolle. c - gynoecial branch, B. zonulata Meagher. d - two androecial branches, B. serpentina (Nees) Trevis. Scale bars $=1 \mathrm{~mm}$.

\section{MICROPHYLLOUS VENTRAL-INTERCALARY BRANCHES}

Microphyllous ventral-intercalary branches (commonly but erroneously called flagella) may be branched or unbranched, and may bear scattered rhizoids or none at all. Their function appears to be to anchor the plant to the substratum, and they are probably able to grow into new plants if the plant is separated from the substratum.

It has also been widely thought that microphyllous branches arise at random intervals along the stem, but this seems to be incorrect. Figure 4 shows their positions on a random selection of plant segments of seven species examined during this study. It can be seen that, with almost no exceptions, each microphyllous branch that arises from the stem on the distal side of a terminal branch has a 'sibling' in a similar position on the branch. Most excep- tions occur when the stem (or branch) branches again before a microphyllous branch has been produced, while the branch (or stem) does not. The development of a sexual branch or a leafy ventralintercalary branch does not interrupt this pattern. The trigger for the development of microphyllous branches is thus likely to be environmental (e.g., temperature, day length, moisture), and does not seem to be the same trigger or triggers for the development of leafy ventral-intercalary branches and sexual branches.

The arrangement of microphylls on the branch follows the 'two lateral + one ventral' arrangement on normal stems, but the microphylls bear only a cellular resemblance to normal leaves and underleaves. The 'ventral' side of the microphyllous branch is nearest the underleaf at the branching point. Microphyllous branches from which further ventral-intercalary branching 
occurs are occasionally found, and the branches so formed may have any of the four forms of ventral-intercalary branching listed above, although microphyllous branching is almost always the case. It is noteworthy that Lindenberg and Gottsche (1851) found gynoecia on branches arising from the microphyllous branches in their description of Bazzania tridens (Rein., Blume $\&$ Nees) Trevis. (as Mastigobryum). I found the same in many specimens, notably one of $B$. francana (Stephani) N. Kitag. (MELU-3210) in which gynoecia were very common and always arose from a microphyllous branch.

Microphyllous ventral-intercalary branches are not unique to Bazzania. For example, species of
Acromastigum Evans develop them (Evans 1912), and some species of Telaranea such as T. clatritexta (Steph.) J. J. Engel \& Merrill may develop Acromastigum-like stoloniform branches (Engel \& Merrill 2004).

\section{LEAFY VENTRAL-INTERCALARY BRANCHES}

Leafy ventral-intercalary branches are produced by all the species examined in this study, and in some - notably B. monilinervis (Lehm. \& Lindenb.) Trevis., B. nitida (F. Weber) Grolle, B. tessellata Meagher and B. vittata (Gottsche) \& Trevis. - the frequency is very high in comparison to other types of branches (Table 1; Fig. 3b). That this type of

Table 1. Branching frequency in 25 Australasian Bazzania Gray species.

\begin{tabular}{|c|c|c|c|c|c|c|}
\hline \multirow{2}{*}{ Species } & \multicolumn{2}{|c|}{ Terminal } & \multicolumn{2}{|c|}{$\begin{array}{l}\text { Ventral- } \\
\text { intercalary }\end{array}$} & \multicolumn{2}{|c|}{ Sexual } \\
\hline & dext. & sinist. & micro. & leafy & gyn. & andr. \\
\hline B. accreta & 21 & 39 & 76 & 1 & 0 & 0 \\
\hline B. adnexa & 12 & 24 & 38 & 4 & 5 & 0 \\
\hline B. amblyphylla & 2 & 10 & 78 & 22 & 0 & 0 \\
\hline B. corbieri & 25 & 19 & 133 & 1 & 0 & 0 \\
\hline B. densa & 25 & 28 & 139 & 13 & 0 & 0 \\
\hline B. fasciculata & 7 & 4 & 37 & 9 & 0 & 0 \\
\hline B. filiformis & 34 & 14 & 103 & 9 & 0 & 0 \\
\hline B. francana & 18 & 41 & 149 & 3 & 0 & 1 \\
\hline B. fuhreri & 42 & 10 & 106 & 4 & 0 & 0 \\
\hline B. gedeana & 14 & 9 & 158 & 24 & 0 & 0 \\
\hline B. hochstetteri & 8 & 4 & 61 & 13 & 0 & 0 \\
\hline B. involuta & 17 & 21 & 25 & 4 & 0 & 0 \\
\hline B. mittenii & 5 & 24 & 39 & 6 & 12 & 0 \\
\hline B. monilinervis & 6 & 28 & 26 & 37 & 0 & 0 \\
\hline B. nitida & 7 & 2 & 38 & 20 & 0 & 0 \\
\hline B. novae-zelandiae & 20 & 21 & 32 & 2 & 0 & 0 \\
\hline B. parisii & 13 & 19 & 108 & 5 & 0 & 0 \\
\hline B. rimosa & 4 & 5 & 74 & 1 & 0 & 0 \\
\hline B. sauropoda & 25 & 18 & 85 & 5 & 13 & 0 \\
\hline B. sp. 'Port Davey' & 11 & 6 & 53 & 7 & 0 & 0 \\
\hline B. tessellata & 11 & 13 & 78 & 27 & 0 & 0 \\
\hline B. tayloriana & 2 & 6 & 38 & 27 & 0 & 0 \\
\hline B. vittata & 0 & 0 & 31 & 42 & 0 & 10 \\
\hline B. wattsiana & 4 & 8 & 21 & 15 & 0 & 1 \\
\hline B. zonulata & 6 & 9 & 42 & 18 & 1 & 0 \\
\hline Total & 339 & 382 & 1768 & 319 & 31 & 12 \\
\hline
\end{tabular}



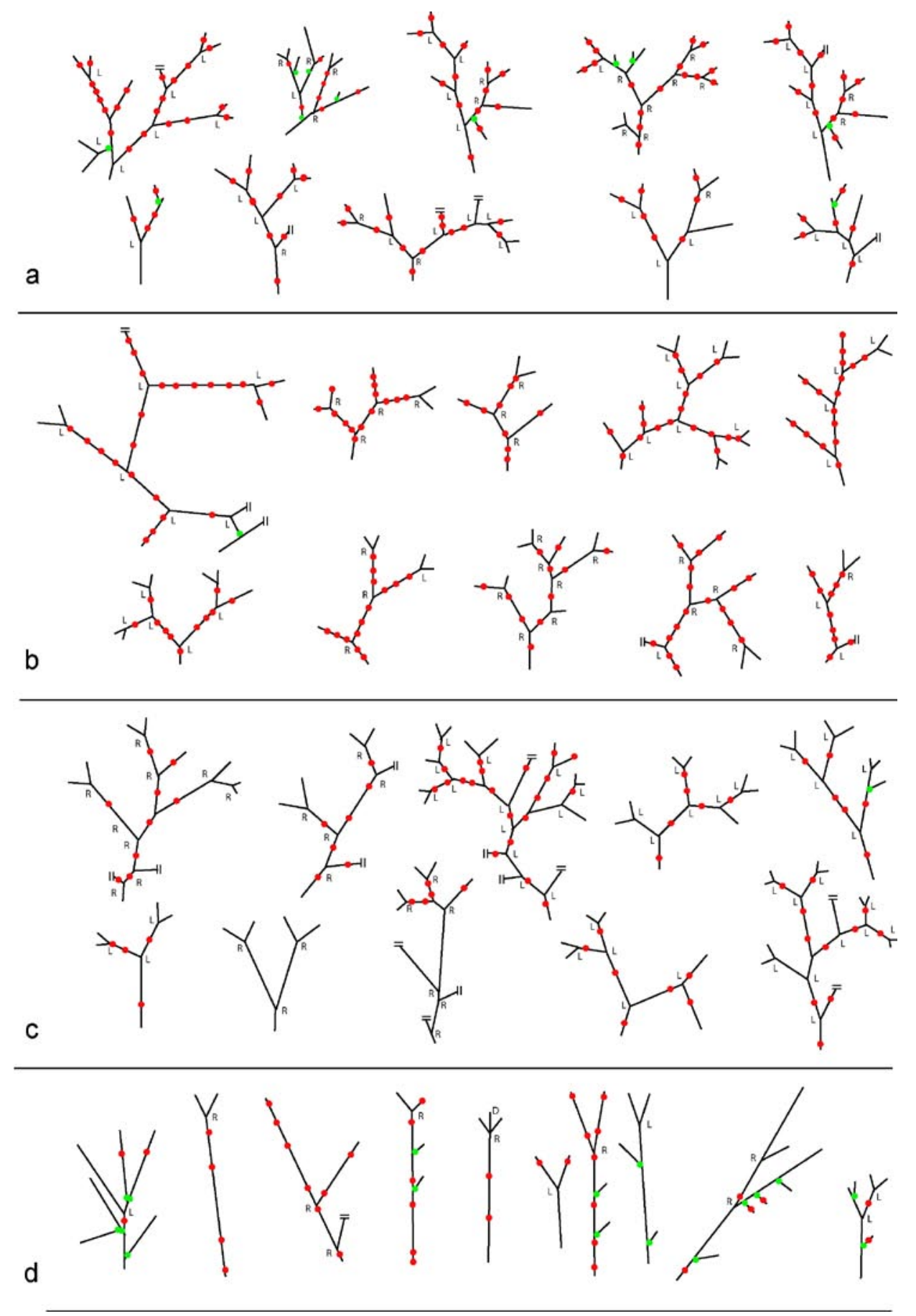

Fig. 4. Position of microphyllous branching $(\bullet)$ and leafy ventral-intercalary branching $(\bullet)$ on randomly selected shoots of Bazzania species. a - B. filiformis Stephani. b-B. corbieri (Stephani) Meagher. c - B. accreta (Lehm. \& Lindenb.) Trevis. d - B. fasciculata (Stephani) Meagher. R, L indicate right (dextrorse) or left (sinistrorse) branch, $=$ indicates broken stem. 

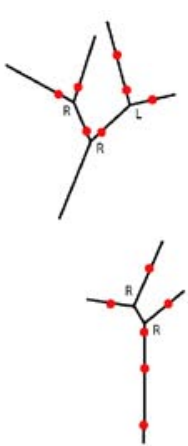

e
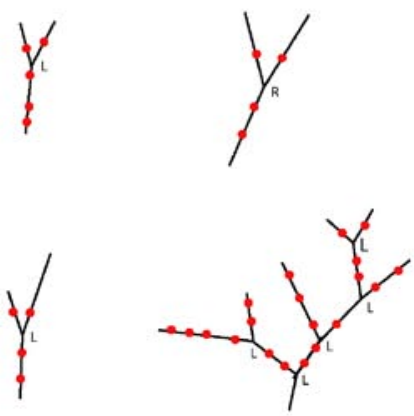
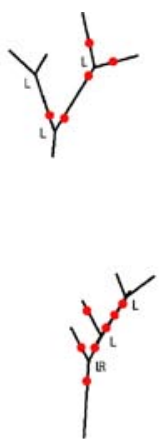
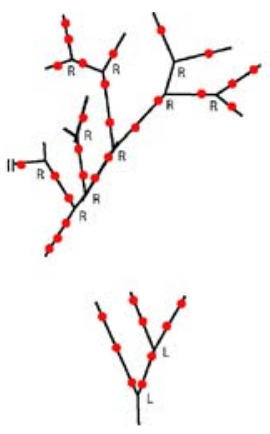

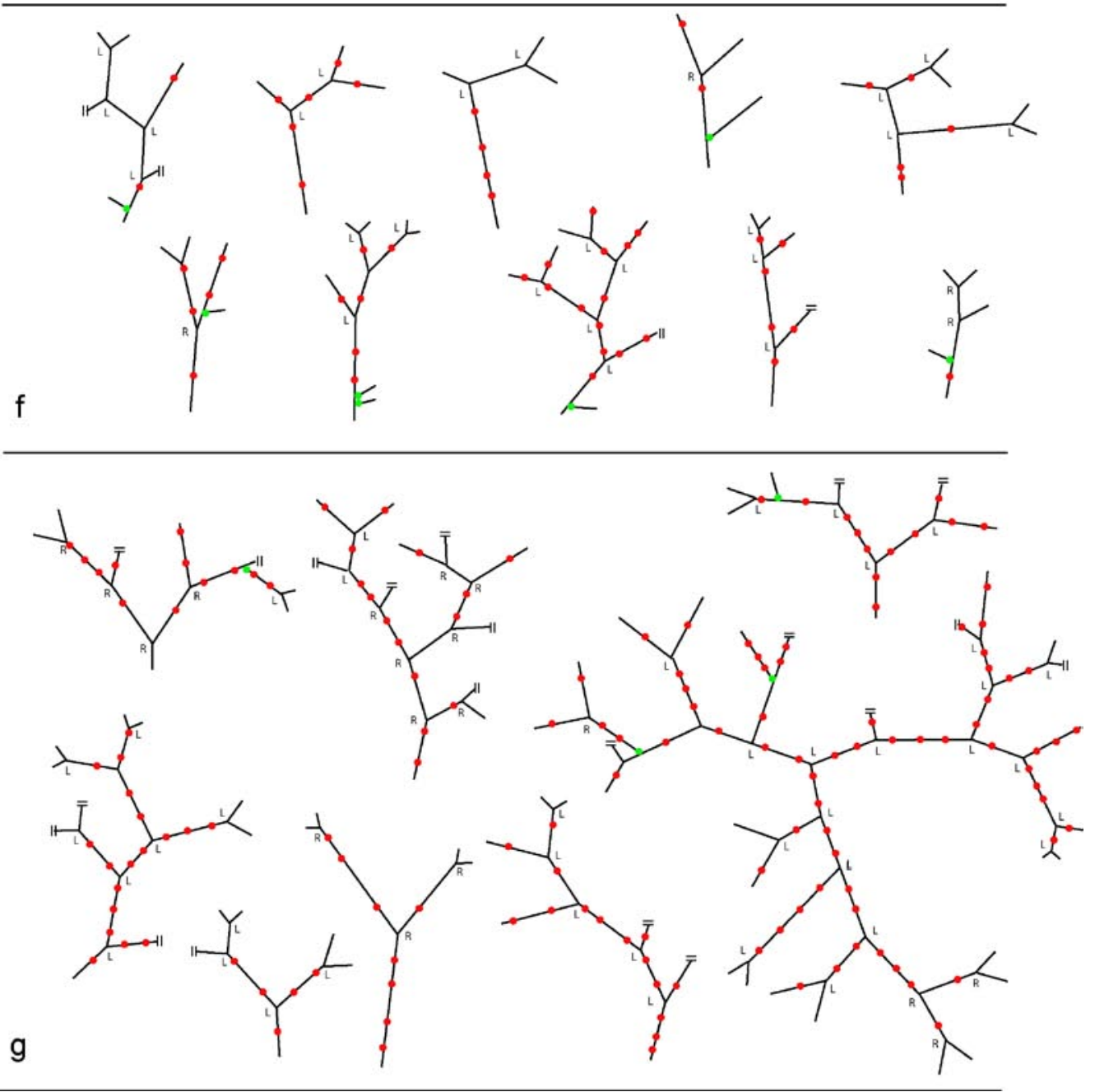

Fig. 4. (Continued). Position of microphyllous branching $(\bullet)$ and leafy ventral-intercalary branching $(\bullet)$ on randomly selected shoots of Bazzania species. e - B. parisii (Stephani) N. Kitag. $\mathrm{f}-$ B. mittenii (Mitt.) Kuntze. g - B. francana. $\mathrm{R}, \mathrm{L}$ indicate right (dextrorse) or left (sinistrorse) branch, $=$ indicates broken stem. 
branching may be merely a random event and therefore not useful as a species character is suggested by a specimen of B. nitida (CBG-9409799), in which all ventral-intercalary branches are the leafy type on some shoots, none are leafy on some shoots, and both leafy and microphyllous types are present on the remaining shoots.

Crandall (1969) stated that leafy ventral-intercalary branches arise only on decapitated stems of Bazzania (that is, the decapitation of a stem initiates the development of a ventral leafy branch). However, in this study I found that most leafy ventral-intercalary branches arose on stems that were not decapitated (e.g., Figs $3 b \& 4 a, d)$. I also noted that shoots often broke at the junction of a leafy ventral-intercalary branch when disentangling them, particularly if this was done when the plant was dry. In fresh material this was readily apparent because fractured cells still contained chloroplasts. Furthermore, I often found the two separated parts of the stem and was able to realign them as they had been in the original plant. It therefore seems likely that Crandall merely mistook cause for effect.

Leafy ventral-intercalary branches are not microphyllous branches on which the leaves and underleaves have developed from microphyllous leaves, as intermediates do not occur; asexual ventral-intercalary branches are either entirely microphyllous or entirely leafy. Furthermore, microphyllous branches always grow perpendicularly from the stem, whereas leafy branches in almost every case bend at right angles immediately on emerging from the stem, so that they have almost the appearance of normal terminal branches when seen from the dorsal side of the shoot, and are often very difficult to differentiate from terminal branches. This is probably why the high frequency of leafy ventral-intercalary branching found in this study has not been reported previously. However, the absence of a dorsal half-leaf at the branching point distinguishes leafy ventral-intercalary branches from terminal branches. The leafy branches also appear to have a much thicker stem when compared to microphyllous branches, although I have not collected data on this character.

\section{CONCLUSIONS}

- Terminal branching in Bazzania may be sinistrorse, dextrorse, or a combination of both in any one plant.

- Terminal branching in Bazzania may be homodromous, antidromous, or a combination of both in any one plant.

- Intercalary branches in Bazzania are always ventral and may be microphyllous, leafy, gynoecial or androecial.

- Microphyllous ventral-intercalary branches in Bazzania appear to develop in a regular pattern in which a branch on a stem has a 'sibling' on the adjacent stem-branch.

- The development of leafy ventral-intercalary branches in Bazzania is not dependent on the fracture of a stem or stem-branch.

- Unlike microphyllous branches, leafy ventralintercalary branches in Bazzania are not geotropic, instead usually being bent so that they lie in the same plane as the stem and stem-branches.

- Gynoecia and androecia in Bazzania usually arise from short ventral branches, but may also develop from microphyllous and leafy ventralintercalary branches.

- Gynoecia usually but not always develop in the distal parts of plants. Androecia usually but not always develop in the proximal parts of plants.

ACKNOWLEDGEMENTS. I am very grateful to Dr. Jiří Váňa for important corrections to the original manuscript. I also thank Dr. Gillian Brown (MELU), Dr. Elizabeth Brown (NSW) and Dr. Chris Cargill (CANB) for organising loans of specimens.

\section{REFERENCES}

CRANDAll B. J. 1969. Morphology and development of branches in the leafy Hepaticae. Nova Hedwigia Beih. 30: $1-261$.

Engel J. J. \& MerriLl G. L. S. 1994. Studies of New Zealand Hepaticae. 8-13. Bazzania and Acromastigum. Bryologist 97(3): 313-320.

Engel J. J \& Merrill G. L. S. 2004. Austral Hepaticae. 35. A taxonomic and phylogenetic study of Telaranea (Lepidoziaceae), with a monograph of the genus in temperate Australasia and commentary on extra-Australasian taxa. Fieldiana, Bot. 44: 1-265. 
Evans A. W. 1912. Branching in the leafy Hepaticae. Ann. Bot. 26(1): 1-27.

GROLLE R. 1964. Über neue bemerkenswerte AcromastigumArten. Oesterr. Bot. Z. 111: 240-256.

LEITGEB H. 1871. Über die Verzweigung der Lebermoose. Bot. Zeitung (Berlin) 29: 557-565.

Lindenberg J. B. W. \& Gottsche C. M. 1851. Species Hepaticarum. Henry et Cohen, Bonn.
SCHUSTER R. M. 1984. Comparative anatomy and morphology of the Hepaticae. In: R. M. SCHUSTER (ed.), New Manual of Bryology. 2: 760-891. Hattori Botanical Laboratory, Nichinan, Japan.

SCHUSTER R. M. 2000. Austral Hepaticae I. Nova Hedwigia Beih. 118: 1-515.

SChuster R. M. \& Schofield W. B. 1982. On Dendrobazzania, a new genus of Lepidoziaceae (Jungermanniales). Bryologist 85(2): 231-238.

Received 3 May 2013 